\title{
Humanizing Vilnius Old Town by the Sump Measures: when Less is More
}

\author{
Marija Burinskiené $^{1 *}$, Vaida Vabuolyte $\dot{e}^{2}$, Gintaras Stauskis ${ }^{3}$ \\ ${ }^{1,2}$ Department of Roads, Vilnius Gediminas Technical University, Vilnius, Lithuania \\ ${ }^{3}$ Department of Urban design, Vilnius Gediminas Technical University, Vilnius, Lithuania
}

Received 14 February 2020; accepted 20 April 2020

\begin{abstract}
The Old Town of Vilnius City is a valuable site included in the UNESCO World Heritage List. One of the most important tasks is to protect the area from noise, pollution, and vibration caused by transport. Currently, over 30,000 vehicles cross the Old Town core daily, most of which do not have a destination in the Old Town, and drivers only use a shorter route to connect within the city. To this purpose, the Vilnius City Municipality has developed a Loop Traffic Scheme in the Old Town of Vilnius, which allows only loop traffic, i.e. for entry/exit to/from a specific restricted area. The main purpose of the article is the discussion and evaluation of measures how the Old Town area can be returned to the people (i.e., pedestrians, cyclists, public transport) to minimize traffic flows and eliminate transit traffic. To achieve smart solutions and to open public spaces for Old Town residents and visitors, we compare different traffic organization and parking measures, analyse their efficiency. We propose integrating innovative technological solutions and smart tools (parking, ridesharing system, integrated pedestrian and bicycle routes, smart traffic control, etc.) by using the best practices of other cities. As a result, we propose the methodology for humanizing open spaces in the Old Town area and beyond.
\end{abstract}

Keywords: humanization, old town, smart tools, traffic management, sustainable communication system.

\section{Introduction}

The Old Town of Vilnius since 1994 is a UNESCO World Heritage Site and is the object of pride of every resident of Vilnius. The Old Town covers an area of 352 ha. It has all the qualities that convey exceptional universal value. The historic center of Vilnius has retained a radial network of streets typical for the Middle Ages. Exceptional objects that remain in the Old Town, such as the Vilnius University Building Ensemble, the Town Hall with its surrounding square, prayer houses of various religious denominations, offices, trading venues, and service offices in many buildings, attract the residents and tourist flows.

Currently, the representative streets of Vilnius transform into open garages, and traffic jams form in the Old Town and Central streets during the "peak" hours. These processes have a negative impact on the living, representational and leisure environment of the Old Town. Observing the current trends in the transport sector, where the highest concentrations of people and cars are, a paradoxical situation can be seen. The residents of Lithuanian cities who do not take advantage of the compactness of a small country are massively buying cars. As the level of motorization increases (560 cars / 1000 inhabitants in Vilnius), negative consequences for society and the environment, such as congestion, occupation of public spaces by cars, noise, traffic accidents, emissions, adverse health effects, and disorders, are increasingly occurring. The main challenge is to focus on the human and to minimize the harmful effects on the environment by using smart technologies to organize communication in the central parts of cities and the old towns.

\section{Literature review}

To evaluate what measures can be applied to humanize the Old Town of Vilnius City, the experience of cities solving similar issues in foreign countries was used. The main aim is to make it possible to use non-motorized vehicles, public transport or better walking on the historic part of the city, as well as eliminating transit through the Old Town area. To create a system of pedestrian and bicycle routes, to ensure harmonious, comfortable and safe communication in the

*Corresponding author. E-mail: marija.burinskiene@vgtu.lt 
Old Town. Not only European but also Asian, Latin American and other cities have such accumulated experience in this field that we analyse.

For example, in Cairo, Egypt the physical and cultural revitalization has proved successful. A less successful aspect, as pointed out by interviewees, was the economic revitalization, due to land-use change, real estate speculation and the need for effective economic policies. Concerning social revitalization, primary and community stakeholders highlighted the impact of prospect gentrification and sanitization policy of public spaces (Elsorady, 2018). The availability and equal access to services is an important aspect in optimising the downtown mobility as to avoid gentrification and other negative socio-economic effects.

Compared to earlier times, many developments, such as longer life expectancies, less working time, timesaving appliances, convenience of prepared foods and eating outside, and speedier transport, has profoundly changed people's lives in modern society. Many developed countries have entered the "leisure era". Shanghai, as an international metropolis, also welcome the era's coming. A high level of urbanization contributes significantly to an increase in leisure time (Yang, 2017). The planned mobility changes should also bring more comfort and leisure opportunities for people.

By Umaña-Barrios and San Gil (2017) research, today, 70\% of the world's poor part are women. Women walk distances that are between 11-16\% longer than men, make approximately $15 \%$ more journeys than men and only $3 \%$ of them commute by bicycle. In Latin America and the Caribbean, women are the main users of public transport. Based on interviews and international case study analysis about gender-related mobility needs, these solutions can bring Costa Rica's mobility system closer to sustainability by becoming more inclusive and considerate of women's needs and reducing the need for them to resort to private mobility. Gender-related mobility needs should be carefully minded before taking action in traffic changes in the old town.

Travel time depends on the spatial structure of territories; the adequacy of cycling infrastructure; whether or not detours have to be made; waiting time at crossings, etc. (Rietveld \& Daniel, 2004). The habitual perception is that cycling involves sacrificing time, but this is not necessarily the case, given that bicycles are usually able to avoid or maneuver around traffic jams, which normally delay motorists (Goldsmith, 1992). Hence, for cyclists, the provision of direct routes and a small number of stops clearly contribute to the attractiveness of the bicycle as a transport mode (Rietveld \& Daniel, 2004). Despite the possibility of exercising be an important factor for cycling (Bergström \& Magnusson, 2003; Freitas \& Maciel, 2017) the perceived convenience of a trip declines with an increase in travel time, since longer travel times and having to spend more effort would lead to less interest in cycling (Heinen et al., 2010). Further, physical disabilities and bad fitness may limit bicycle use for some individuals. Therefore cycling safety and comfort should be a key goal while planning mobility changes in urban downtown.

Historic and cultural area refers to an area where historical buildings concentrate, and the architectural style, spatial pattern and street landscape reflects the geographical and cultural characteristics of a particular historical period of Shanghai. Core built-up areas of Shanghai include downtown and sub-center. These areas are where people concentrate, living and working. Therefore, the recreational trail system should pay special attention to these areas and provide enough trails to meet the needs of people exercising near where they live. Tourism, culture, sports, and historic resources are important components of the recreational trail system. Urban recreation should be minded in drafting the policy measures for optimising mobility patterns in the old town.

Through the planning and construction of the urban recreational trail system, the essences and characteristics of the city are excavated. The urban recreational trail system is aiming to enhance urban liveability. It encourages the public to use it (Yang, 2017). The installed mobility reorganizing measures should allow urban areas to stay liveable and vibrant.

The innovative means of traffic regulations operate in downtown areas, one of the most relevant issues is the regulation of car parking. For this reason, used "Downtown congestion pricing" (DCP to drive in a city's central areas. Five major cities have implemented DCP: Singapore, London, Stockholm, Milan, and Gothenburg (Lehe, 2019). This may be the useful environmental policy for reducing congestion in the old town.

The urban truck deliveries make a big impact on commuter parking, because of the shared use of parking spaces. The inelasticity of freight demand, and the need to double-park when no spaces are available due to need for proximity. Nonetheless, the literature on downtown on-street parking generally continues to exclude truck delivery behaviour. One of the long-term objectives of this research is to provide a dynamic (per unit time) snapshot model of downtown parking for designing parking informatics systems. Unlike the ones proposed in the literature, there is a need for parking and delivery information systems for both commuters and delivery van drivers (Amer \& Chow, 2017; Zagorskas \& Burinskienė, 2020). For this reason, the ICT systems should be applied in optimising old town mobility and especially parking.

The planners and developers have contradicted opinion for downtown area development. The developers have gradually acknowledged the extra value of the downtown area as a unique location for luxury apartments they challenged established downtown land-use regulations of such areas. Under these circumstances, planners faced great difficulties in promoting their corporate-complex agenda forcing them to work with the market so that that part of their objectives could be fulfilled (Charney, 2015). 


\section{Transportation in Vilnius Old Town}

The City of Vilnius aims to reorganize transport links in the Old Town of Vilnius in such a way as to focus on people and significantly reduce the increasing environmental impact of motor transport. Also, apply the principles of a smart city to improve the urban environment, humanize it and create spaces without cars (Master plan..., 2007; Damidavičius et al., 2019).

On July 13, 2011, Vilnius City Municipality Council decision, “On the approval of the Provisions for Local Toll Charges for the Use of Parking Areas Established by the Council" approved the change in the boundaries of the local toll zones presented in Figure 1.

Following the recommendations and experience of foreign countries, in cases where more than $85 \%$ of parking spaces are recorded occupied in individual streets or territories, adjustment of the local toll rates shall be initiated. The analysis of the occupancy of the parking places in the tolled places of Vilnius city was carried out in April - May 2016 and in 2017 by the order of the Municipal Enterprise (ME) "Susisiekimo paslaugos" (Mobility Services). The survey results showed that most of the parking spaces in the red and blue areas are overcrowded. Therefore, by the decision of the Vilnius Municipality, the Blue Zone was expanded in 2017 to include B. Radvilaite, Islandija, Vilnius, Liejykla, Totoriai, L. Stuoka-Gucevičius, Pilies, Šv. Jonas, Dominikonai, Benediktinai, Labdariai Streets and S. Daukanto Square. In 2017, Vilnius City Council changed the rates of two local toll zones: the red zone from EUR 0.9 to EUR 1.5 per hour and the blue zone from EUR 1.8 to EUR 2.5 per parking hour. Starting January 1, 2020, the boundaries of the charged parking areas have been expanded (Figure 1).

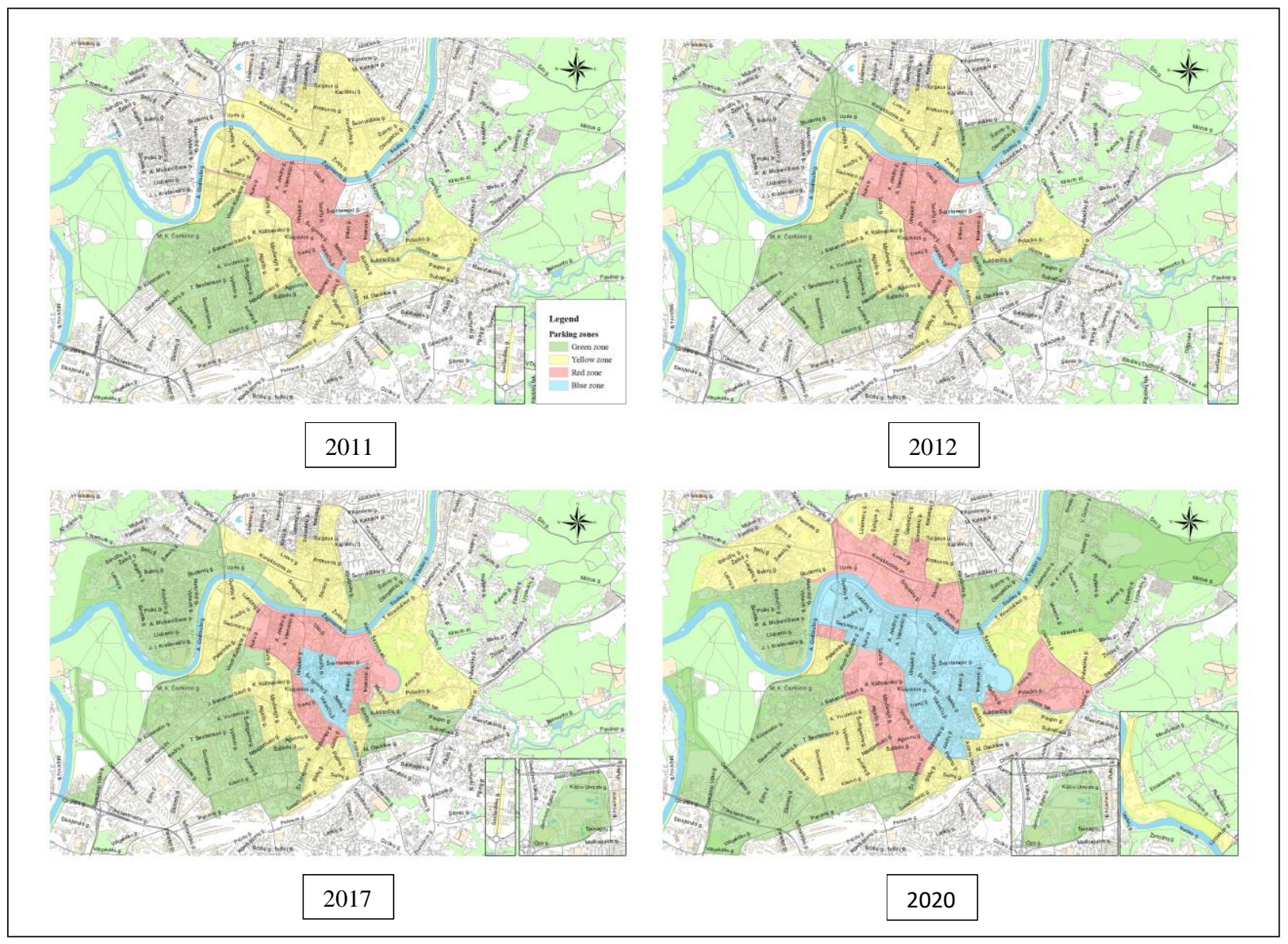

Figure 1. Dynamics of Vilnius city paid parking zones 2011-2020

Local tolls are levied of drivers, paying by parking machines, short message services or using mobile apps, developed by the ME "Susisiekimo paslaugos". Current Vilnius local toll rates for parking in separate toll zones presented in the Table 1 below.

Compared to other Baltic State capitals, the first hour of parking in the Old Town in Riga costs 5 EUR and each additional hour costs 8 EUR. Since 2013, the Latvian capital has switched to a complex tariff, where each additional hour is more expensive than the first one. In Tallinn in 2015, from 4.8 EUR per hour for parking in the Old Town to the rate of 6 EUR per hour was changed (Table 2). 
Table 1. Local toll rates for parking a vehicle in Vilnius (source: ME "Susisiekimo paslaugos")

\begin{tabular}{|c|c|c|c|}
\hline & Toll parking & Monthly fee* $^{*}$ & Reserved lot** $^{* *}$ \\
\hline Zone & Minimum parking time and price & 1 month/1 vehicle & 1 month/1 space \\
\hline Blue & $12 \mathrm{~min}-0.50 \mathrm{EUR}$ & - & $525.00 \mathrm{EUR}$ \\
\hline Red & $12 \mathrm{~min}-0.30 \mathrm{EUR}$ & - & $315.00 \mathrm{EUR}$ \\
\hline Yellow & $10 \mathrm{~min}-0.10 \mathrm{EUR}$ & $67.00 \mathrm{EUR}$ & $126.00 \mathrm{EUR}$ \\
\hline Green & $20 \mathrm{~min}-0.10 \mathrm{EUR}$ & $33.00 \mathrm{EUR}$ & $63.00 \mathrm{EUR}$ \\
\hline White & - & - & $36.00 \mathrm{EUR}$ \\
\hline
\end{tabular}

Table 2. Parking rates in the capitals of the Baltic States in the Old Town area (source: Compiled by authors)

\begin{tabular}{|c|c|c|}
\hline City & Restriction of parking time & Price for central parking for 1 hour \\
\hline Vilnius & Not applicable & 2.5 EUR \\
\hline Riga & Applicable & 5 EUR first hour / 8 EUR \\
\hline Tallinn & Not applicable & 6 EUR \\
\hline
\end{tabular}

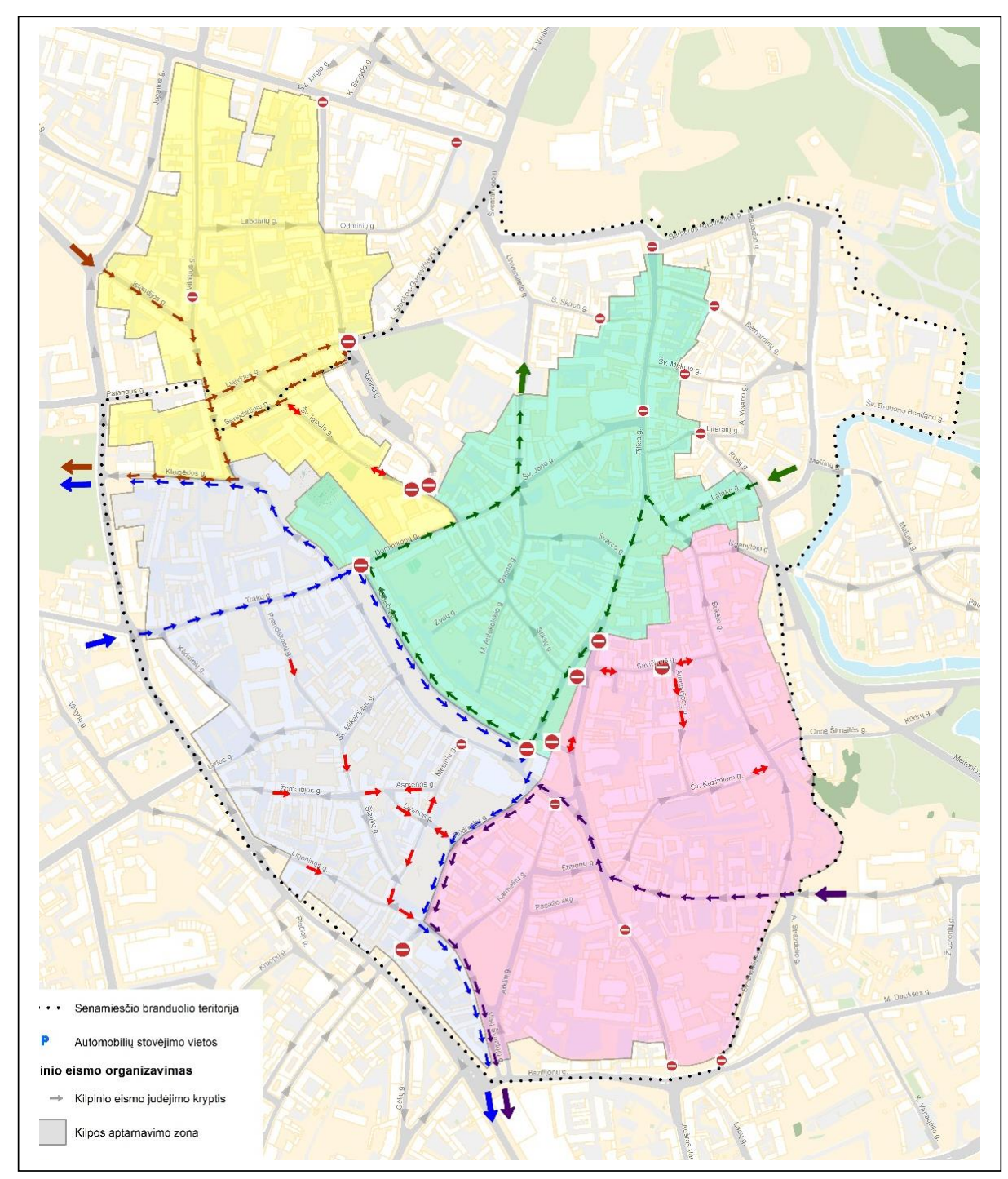

Figure 2. The scheme for the loop traffic organization in Vilnius Old Town (source: Vilniaus Planas) 
For presenting the complete picture about the mobility development in Vilnius Old Town we should have a look at the way it has been traditionally functioning for several decades. Despite the growth of Vilnius City in the territory and the number of residents, the way car traffic is still running in the Old Town remained essentially unchanged. That mainly concerns some traffic flows cutting through the Old Town since the 70ties of the 20th c. The amount of vehicles in the city has increased more than five times throughout that period, and consequently, the traffic flows in the Old Town have increased. In addition, a lot of open space was taken away from public use and given for car parking. The real traffic intensity has evidently compromised traffic safety and radically reduced the comfort for visitors and residences. During the last decade, the plans for making radical changes in the Old Town have been discussed several times. The planning and mobility professionals have prepared several visions but they all were disapproved by the local politicians because of a short-handed lobby of the shop and restaurant owners in the Old Town. It turned to be evident that the businesses lack a long-term perspective on humanizing the Old Town environment and making the long-waited changes, firstly cutting the through traffic across the Old Town area. The recent attempt seems to have more political support, nevertheless, the prepared re-organizing plan - the Loop Scheme (Figure 2) - is a compromise between the human needs and the business interest. The recent proposal by the ME "Susisiekimo paslaugos" still lacks higher ambition in several places where the loops are very long; e.g., it is proposed to leave the two-way traffic on the busiest and publicly favored Vokiečiu str. (see the thick arrow in the scheme above).

\section{Methodology of traffic reorganization in Vilnius Old Town}

To develop a consistent methodology for the humanization of the Old Town of Vilnius, it is necessary to set the main goal and formulate the tasks that would allow achieving this goal. Many issues have to be resolved when reorganizing the transport system of the Old Town of Vilnius to ensure priority for pedestrians, cyclists and public transport. Based on our previous research, literature analysis and on-site investigation these are the main aspects:

1. The planning and organization of the road traffic shall determine which streets shall be permitted for driving as well as the formation of loop traffic has to be planned as to avoid through traffic flows in the Old Town area;

2. To analyze where the cars are located in the Old Town area, the existing parking lots, their capacity, load. It is necessary to answer the question, how to reduce the need for parking spaces, where to park them and how to compensate for the parking spaces for the residents of the Old Town and its guests and gradually change their mobility patterns;

3. To use a ridesharing system in the Old Town (Ušpalyte-Vitkuniene et al., 2018), to evaluate the advantages of the rideshare vehicles in the territory and their settlement system with Vilnius City Municipality, and to plan relevant compact spaces for the shared vehicles deployment;

4. To adjust the routes of public transport to ensure that the selected ones provide equal accessibility to the Old Town area for the residents and city visitors;

5. Organization of bicycle and scooter traffic as to ensure safe and comfortable trip in the Old Town area, selecting their permanent parking spots, and determining the number of vehicles therein;

6. Pedestrian routes throughout the Old Town and their extension into the surrounding areas as to ensure convenient access to the objects of attraction, as well as the integrity of the routes and their continuity to the city center (Dičiūnaitè et al., 2018).

7. To adjust the delivery services to the Old Town, synchronising its access in time and space, especially for weekends and days-off;

8. Using the smart technologies: additional smart signs and horizontal signage for implementing traffic changes, especially to flexibly manage traffic changes during weekends and holidays.

9. Identify the main urban open (public) spaces, their purpose, specification, utilization, adaptation to the humanization of the Old Town territory, promoting the individuality of different public areas;

10. Identifying the main objects of attraction, their potential, connection, delivery and parking needs, to gradually reduce the need for short and long-term parking in the Old Town area by gradually eliminating the number of street parking spaces.

11. Aesthetics, sustainability, development, humanizing the Old Town of Vilnius, encouraging the return of spaces to the public, taking into account the past evolution of communication and environmental aesthetics should be minded.

12. Adaptation and use of local landscape: plants, water features, terrain features (existing, prospective) for the humanization of the Old Town.

The humanization of the Old Town area of Vilnius should be adapted to the harmonious communication between residents and guests using innovative modern technologies. In individual locations, these may include intelligent parking systems, using parking detectors or CCTV cameras, limiting traffic, parking time or traffic volume (Sustainable urban..., 2018). Apply smart road signs with variable information. There may be reverse traffic, limited servicetransport access to the Old Town area at certain times of the day. Entering car counting and determining the number of cars in the inner loop, allows managing when to begin restricting access to the Old Town area. Only allow ultra- 
low-emission or low-emission cars to enter the Old Town. Real-time information for street users, including pedestrians. Prohibit the parking of tourist buses in or near the Old Town of Vilnius, leaving only landing areas. Use of mobile devices to receive information from the relevant apps (Traffi, m.Ticket, etc.). The utilization of each of these technologies must be justified through cost-benefit calculations.

\section{Conclusions}

The main purpose of the article is the discussion and evaluation of how the Old Town area can be returned to the people (i.e., pedestrians, cyclists, public transport) to minimize traffic flows and eliminate transit traffic through the Old Town area. To achieve smart solutions and to open public spaces for Old Town residents and visitors. For this reason, we propose to use means listed below:

- To reduce pollutant emissions in the Old Town of Vilnius and to free up urban spaces for human communication and recreation, it is necessary to stimulate people's interest in energy-efficient vehicles and new advanced technologies.

- For achieving the humanizing goal, it is important to promote the use of public and non-motorized transport in the Old Town area, giving the priority to the re-use of urban car-occupied spaces as parking lots and onstreet parking.

- The other necessary measure is restricting access to the Old Town area by cutting out transit traffic and gradually reducing the number of on-street parking spaces to zero, also allocating green areas for public spaces instead.

- The application of traffic management information system and intelligent parking management system is another efficient measure that will allow for flexible use of Old Town spaces and especially changing their mode of use over time.

- Integrating urban land use, public space and transport planning will allow reducing travel demand and increase public transport share in the Old Town area.

- To make all the changes happen it is essential to involve the city community to participate in decisionmaking to humanize the city centre public spaces, utilize smart models of the visual environment, apply proactive approaches to involving the public and use surveys to assess the situation as long as it changes.

To achieve all above, we should apply the methodology of the Old Town humanization consistently, by giving very clear answers to the 12 questions mentioned in the article, thus ensuring the humanization of the Old Town in Vilnius City and in the other Baltic Sea Region capitals.

\section{References}

Amer, A., \& Chow, J. Y. (2017). A downtown on-street parking model with urban truck delivery behavior. Transportation Research Part A: Policy and Practice, 102, 51-67. https://doi.org/10.1016/j.tra.2016.08.013

Bergström, A., \& Magnusson, R. (2003). Potential of transferring car trips to bicycle during winter. Transportation Research Part A: Policy and Practice, 37(8), 649-666. https://doi.org/10.1016/S0965-8564(03)00012-0

Charney, I. (2015). Downtown redevelopment and land-use regulation: Can planning policies discipline property development? Land Use Policy, 47, 302-308. https://doi.org/10.1016/j.landusepol.2015.04.019

Damidavičius, J., Burinskienè, M., \& Ušpalytė, R. (2019). A monitoring system for sustainable urban mobility plans. The Baltic Journal of Road and Bridge Engineering, 14(2), 158-177. 10.7250/bjrbe.2019-14.438

Dičiūnaitė-Rauktienė, R., Gurskienė, V., Burinskienė, M., \& Maliene, V. (2018). The usage and perception of pedestrian zones in Lithuanian cities: Multiple criteria and comparative analysis. Sustainability, 10(3), 818. https://doi.org/10.3390/su10030818

Elsorady, D. A. (2018). Revitalisation of Downtown Khedive Cairo: A contested sovereignty. Cities, 73, 51-62. https://doi.org/10.1016/j.cities.2017.10.009

Freitas, A. L. P., \& Maciel, A. B. L. (2017). Assessing cyclists' perceptions, motivations and behaviors: an exploratory study in Brazil. Procedia Engineering, 198, 26-33. https://doi.org/10.1016/j.proeng.2017.07.071

Goldsmith, S. A. (1992). Reasons why bicycling and walking are and are not being used more extensively as travel modes (No. 1). Federal Highway Administration.

Heinen, E., Van Wee, B., \& Maat, K. (2010). Commuting by bicycle: An overview of the literature. Transport Reviews, 30(1), 5996. https://doi.org/10.1080/01441640903187001

Yang, Y. (2017). The practice and exploration of Shanghai recreational trail system planning. Procedia Engineering, 198, 127-138. https://doi.org/10.1016/j.proeng.2017.07.077

Lehe, L. (2019). Downtown congestion pricing in practice. Transportation Research Part C: Emerging Technologies, 100; 200223. https://doi.org/10.1016/j.trc.2019.01.020

Master plan of Vilnius city untill 2015. (2007). Aproved in $14^{\text {th }}$ of February 2007 by Vilnius City Council by decision No. 1-1519. Vilnius.

Rietveld, P., \& Daniel, V. (2004). Determinants of bicycle use: Do municipal policies matter? Transportation Research Part A: Policy and Practice, 38(7), 531-550. https://doi.org/10.1016/j.tra.2004.05.003 
Sustainable urban mobility plan of Vilnius city. (2018). Aproved in $19^{\text {th }}$ of December 2018 by Vilnius City Council by decision No. 1-1859. Vilnius.

Umaña-Barrios, N., \& San Gil, A. (2017). How can spatial design promote inclusivity, gender equality and overall sustainability in Costa Rica's urban mobility system? Procedia Engineering, 198, 1018-1035. https://doi.org/10.1016/j.proeng.2017.07.147

Ušpalyte-Vitkuniene, R., Burinskiene, M., \& Stauskis, G. (2018, December). GIS application for stimulating car-sharing activity. In 2018 International Joint Conference on Information, Media and Engineering (ICIME) (pp. 215-219). IEEE. 10.1109/ICIME.2018.00052

Zagorskas, J., \& Burinskienè, M. (2020). Challenges caused by increased use of e-powered personal mobility vehicles in European Cities. Sustainability, 12(1), 273. https://doi.org/10.3390/su12010273 